$$
\begin{aligned}
& 5-5 \\
& 00
\end{aligned}
$$




\title{
Os corpos infantis nas instituições de acolhimento'
}

\section{Los cuerpos infantiles en las instituciones de acogida // The infant bodies in refuge institutions}

\author{
Alexandre Paulo Loro \\ Universidade Federal da Fronteira Sul, Brasil \\ alexandre.loro@uffs.edu.br
}

Revista Corpo-grafías: Estudios críticos de y desde los cuerpos / Volumen 7 - Número 7 / Enero - diciembre 2020 / ISSN impreso 2390-0288, ISSN digital 2590-9398 / Bogotá, D.C., Colombia / 69-79

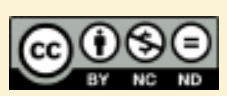

Fecha de recepción: 17 de enero de 2019 Fecha de aceptación: 4 de mayo de 2019

DOI: https://doi.org/10.14483/25909398.15506

Cómo citar este artículo: Loro, A. P. (2020, enero-diciembre). Os corpos infantis nas instituições de acolhimento. Revista Corpo-grafías: Estudios críticos de y desde los cuerpos, 7(7), pp. 69-79 ISSN 2390-0288.

\footnotetext{
$1 \quad$ Articulo de Investigación: El presente artículo deriva de la investigación realizada desde un proyecto de extensión desarrollado durante el curso académico 2018, en una institución de apoyo social y educativo en Chapecó, Santa Catarina, Brasil.

2 Pós-doutorando em Ensino na Universidade Estadual do Paraná (UNESPAR), com estágio realizado na Universidade de Valência (UV). Doutor em Educação Física pela Universidade Estadual de Maringá (UEM), com Estágio Sanduíche no Centro de Estudos Sociais da Universidade de Coimbra (CES/UC). Mestre em Educação pela Universidade Federal de Santa Maria (UFSM). Licenciatura Plena em Educação Física (UFSM). Professor Adjunto da Universidade Federal da Fronteira Sul (Campus Chapecó-SC). Professor Credenciado como Membro Permanente do Programa de Pós-Graduação Interdisciplinar em Ciências Humanas (PPGICH/ UFFS), Curso de Mestrado (Campus Erechim-RS). Membro do Grupo de Estudos e Pesquisas em Infâncias, Gênero e Corpo na Educação (GEINC/UFFS).
} 


\section{Resumo}

Neste artigo temos como propósito refletir sobre as corporalidades das crianças que vivem suas infâncias no "Serviço de Acolhimento de Crianças e Adolescentes" em Chapecó-SC-Brasil. A metodologia consistiu em proposições (brincadeiras) organizadas em pequenos grupos, realizadas uma vez na semana, pensadas a partir da perspectiva das próprias crianças ( 0 a 6 anos). As ações valorizavam a corporalidade das crianças em sua singularidade, experienciadas por outra temporalidade, diferente dos adultos, que tendem a criar modos de subjetivação atravessados por dispositivos para a manutenção da ordem estabelecida que, por vezes, oscila entre a resistência e as normatizações. As corporalidades podem evidenciar exclusão, fator que requer ações humanizadoras em relação às crianças que se encontram em situação de vulnerabilidade social. As evidências têm demonstrado que esses espaços requerem outras leituras e interpretações dos corpos infantis, por vezes invisibilizados, docilizados e/ou transgressores.

\section{Palavras-chave}

Corpo; dispositivo; infância; instituição

\section{Resumen}

En este artículo tenemos como propósito reflexionar sobre las corporalidades de los niños que viven sus infancias en el "Serviço de Acolhimento de Crianças e Adolescentes" en Chapecó-SC-Brasil. La metodología consistió en proposiciones (juegos) organizadas en pequeños grupos, llevada a cabo una vez a la semana, pensadas desde la perspectiva de los propios niños (0 a 6 años). Las acciones han valorado la corporalidad de los niños en su singularidad, experimentadas por otra temporalidad, diferente de los adultos, que tienden a crear modos de subjetivación atravesados por dispositivos para mantener el orden establecido que, a veces, fluctúa entre la resistencia y las normas. Las corporalidades pueden evidenciar exclusión, factor que requie- re acciones humanizadoras en relación a los niños que se encuentran en situación de vulnerabilidad social. Las evidencias han demostrado que esos espacios requieren otras lecturas e interpretaciones de los cuerpos infantiles, a veces invisibles, dóciles y/o transgresores.

\section{Palabras clave}

Cuerpo; dispositivo; infancia; institución

\section{Abstract}

In this article our purpose is to reflect on the corporalities of the children who live their childhoods in the "Serviço de Acolhimento de Crianças e Adolescentes" in Chapecó-SC-Brazil. The methodological consisted in propositions (games) organized in small groups, held once a week, thought from the perspective of children themselves ( 0 to 6 years). The actions valued the corporality of the children in their singularity, experienced by another temporality, different from the adults, who tend to create modes of subjectivation crossed by devices for the maintenance of the established order that, sometimes, oscillates between the resistance and the norms. Corporalities may show exclusion, a factor that requires humanizing actions in relation to children who are in situations of social vulnerability. Evidence has shown that these spaces require further readings and interpretations of infantile bodies, that sometimes are invisibled, docilized and / or transgressors.

\section{Keywords}

Body; device; childhood; institution

\section{Introdução}

O Estatuto da Criança e do Adolescente (1990), no artigo 5o, determina que nenhuma criança ou adolescente pode ser objeto de qualquer forma de negligência, discriminação ou exploração, violência ou crueldade e 
opressão, pois crianças e adolescentes devem ser tratadas com prioridade absoluta, e é dever da família, da sociedade e do Estado assegurar estes direitos e garantias, dando-Ihes proteção integral, de forma a evitar situações de risco social. Entretanto, quando identificada situação de risco - violência, por exemplo, no âmbito privado (relações familiares) e/ou no âmbito social -, e que o suporte familiar é insuficiente, o Serviço de Acolhimento de Crianças e Adolescentes Municipal é acionado, e as crianças encaminhadas às instituições sociais, criadas para garantir os direitos de maneira permanente, e acabam por substituir, provisoriamente, o papel dos pais e/ou responsáveis.

Compreende-se indivíduos em situação de risco social todos aqueles que, comparados à média de crianças de sua idade, não estão em condições adequadas para desenvolverem-se de maneira integral. Dentre os fatores de risco está o fato de a criança, muitas vezes, ser vítima ou testemunha de abuso físico/emocional/sexual. São crianças que tiveram os seus vínculos fragilizados e que sofreram inúmeros tipos de privações.

Em uma estrutura social desigual, que desencadeia violência e exclusão, as crianças constroem referenciais, buscam identificações nos modelos que estão à sua volta, bem como a contestar as estruturas impostas, e o fazem através de seu corpo, afinal o corpo é concebido socialmente, e a sua análise proporciona vias de acesso à estrutura de grupos específicos (Arpini, 2001). Esses fatores são suficientes para pensarmos em ações humanizadoras em relação às crianças que se encontram em situação de vulnerabilidade social.

As experiências corporais das crianças que vivem no Serviço de Acolhimento estão relacionadas às constantes interações que estabelecem nesse ambiente social, afinal o corpo é uma produção sócio-histórica, política e cultural, em elaboração permanente. Flexível e de materialidade provisória, o corpo evidencia registros que variam com os espaços, tempos, conjunturas econômicas, grupos étnicos, sociais, sexuais e de gênero. Neste artigo temos o propósito de debater o corpo relacional, produzido na socialização e coletividade, e materializado nas corporalidades das crianças que vivem suas infâncias nas/em instituições, em específico, o "Serviço de Acolhimento de Crianças e Adolescentes" de Chapecó-SC-Brasil.

A metodologia de trabalho consistiu na proposição de brincadeiras semiestruturadas, compreendidas em sua dimensão cultural, como um dos meios de as crianças realizarem e agirem no mundo, não apenas para se preparar para ele, mas usando-o como recurso comunicativo para participar da vida cotidiana, na interação social, dando significado às ações (Ferreira, 2004).

A brincadeira é uma atividade que tem um fim em si mesma em sua dimensão livre e espontânea, por esse motivo as ações foram pensadas a partir da perspectiva das próprias crianças (0 a 6 anos). Em 2018 as atividades eram planejadas uma vez por semana pelas acadêmicas do Curso de Pedagogia da Universidade Federal da Fronteira Sul (UFFS) e realizadas com grupos pequenos (dez crianças, aproximadamente). $\mathrm{O}$ atendimento a um número menor de crianças, que contou com o apoio frequente de equipe multidisciplinar, que incluía cuidadoras, propiciou uma rotina próxima do convívio familiar, característica geralmente buscadas pelas instituições de Acolhimento.

Todas as atividades estavam articuladas com o "Grupo de Estudos e Pesquisas em Infâncias, Gênero e Corpo na Educação", e contou com o suporte do "Laboratório de Experiências Lúdicas e Brincadeiras" da UFFS, Campus Chapecó, Santa Catarina, Brasil.

Para o desenvolvimento da pesquisa foi elaborado um roteiro de observação, sendo que as vivências foram registradas em Diário de Bordo em todos os encontros. $\mathrm{O}$ Diário de Bordo é um instrumento de reflexão da prática cotidiana durante a realização das etapas de observação 
e intervenção, que demonstra a sequência dos processos nos quais se desenvolve uma proposta ou determinada teoria - momento em que as proponentes podem transformar o pensamento em registro escrito (documento).

Em que pese o tempo provisório de permanência e as relações interpessoais estabelecidas das crianças no Serviço de Acolhimento de Crianças e Adolescentes, tomamos como problema central a seguinte indagação: como os processos exclusionários permitem (ou não) momentos de ação, criatividade e resistência?

\section{Os corpos infantis institucionalizados}

O cotidiano das crianças na instituição de Acolhimento é marcado pela convivialidade de grupo. É um modo de vida com outras crianças na mesma condição, que edifica a educação do corpo através de rotinas institucionais, que pressupõem o cumprimento de regras, normatizações e disciplina - condutas que se tornam naturalizadas, aceitáveis e adequadas.

Destarte, a forma como as crianças lidam com essas convenções poderá desdobrar diferentes tipos de ajustamentos: a criança incorpora naturalmente as imposições da instituição, mantendo uma conduta que colabora na organização do ambiente (ajuste primário); ou pela não aceitação das imposições, transgredindo aquilo que está posto (ajuste secundário) (Goffman, 2005).

Uma das características dessas instituições é o controle, ao valer-se de dispositivos que limitam experiências da praxiologia motriz. As crianças, ao serem submetidas à normatização da instituição, incorporam o disciplinamento capaz de "docilizar o corpo" (Foucault, 2001). Para assegurar uma disciplina capaz de exercer poder e autoridade do adulto sobre a criança, são arranjadas duas regras fundamentais: "a arte das distribuições" e "o controle da atividade". A primeira abrange a forma funcional como a criança é alocada no ambiente, isto é, define-se e organiza-se o local que ela ocupará; a segun- da regra corresponde à definição de rotinas e o cumprimento de horários - otimização do tempo, seleção de brincadeiras e materiais autorizados para as crianças.

Contraditoriamente, a imposição de limites nas rotinas do Serviço de Acolhimento coexiste com os desvios, pois essas duas categorias estão imbricadas, implicam-se mutuamente, uma vez que a regularidade também cria o desvio, e que a luz e a sombra compõem a complexa trama da teia social (Maffesoli, 2005). ${ }^{3}$

Esta relação de nterdependência não se extingue, pois toda vez que uma criança tem uma conduta desviante e "anormal" as cuidadoras (agentes de controle) criam novos dispositivos para conter a transgressão, em um jogo tensional e ambíguo. Em síntese,

A transgressão é um gesto relativo ao limite; é aí, na tênue espessura da linha, que se manifesta o fulgor de sua passagem, mas talvez também sua trajetória na totalidade, sua própria origem. A linha que ela cruza poderia também ser todo o seu espaço. $O$ jogo dos limites e da transgressão parece ser regido por uma obstinação simples; a transgressão transpõe e não cessa de recomeçar a transpor uma linha que, atrás dela, imediatamente se fecha de novo em um movimento de tênue memória, recuando então novamente para o horizonte do intransponível. Mas esse jogo vai além de colocar em ação tais elementos; ele os situa em uma incerteza, em certezas logo invertidas nas quais o pensamento rapidamente se embaraça por querer apreendê-las. (Foucault, 2009, p. 32)

Os mecanismos de regulação não extinguem a linguagem transgressiva, que é constituinte do sujeito. Outrossim, inexiste o dilema entre limite e transgressão, mas uma ligação, uma relação em espiral, que não se extingue jamais (Motta, 2012). Essa reflexão está presente na obra "Vigiar e

3 Em "A Sombra de Dionísio" está representado o sujeito contemporâneo que exerce vários papéis, impera a convivência dos contrários, independentemente de quais sejam os seus valores, os demais não precisam adotá-los. 
Punir", quando Foucault (2001) menciona que as sociedades são constituídas pela normalização (processo de regulação da vida dos indivíduos e das populações), espaços onde se cruzam, articuladamente, a norma da disciplina e a norma da regulação.

As ações provindas da regulamentação sobre os corpos (tecnologia do poder sobre a população) são formas de domínio (modalidade exercida sobre a população) que materializam discursos reguladores e disciplinares (Biopoder). Para Foucault (1987) o corpo é superfície e cenário de uma inscrição corporal - é a superfície inscrita pelos acontecimentos, engendrados por uma ordem discursiva que regula os prazeres e expressões, deixando-o sempre à deriva; é suficientemente estável para servir como base de autorreconhecimento ou de compreensão genérica das outras pessoas, evidenciando a constância da inscrição cultural que se abate sobre o mesmo.

O Biopoder também é identificável na tentativa de adestramento, na utilidade e na docilidade do corpo pelos procedimentos da constante imposição da disciplina (Peres, 2011).

Cada época e contexto elaboram retóricas corporais, analisá-las é dar visibilidade, é revelar sinais de saúde, tristeza e alegria, vida e morte... enfim, permitir a escrita de múltiplas histórias, dentre elas, da própria educação do corpo, pois nele alojam-se desejos, segredo, mistérios - uma educação moral e não somente física, e, por esses motivos, não podemos pensá-lo como puramente biológico (Soares, 2003).

Em outras palavras, o corpo é historicamente construído - não é somente um conjunto de órgãos, ossos e músculos -, tem uma dimensão política. Crespo (1990), ao enfatizar esta dimensão, destaca que o corpo não é um dado biológico imutável, mas é a origem e a consequência de complexos processos de elaboração social.
No percurso da história a progressão de invenções e intervenções resultaram no aparecimento de dinamismos calculados, que até hoje não cessaram, sendo que o seu entorno envolve inúmeros atributos e significados socioculturais. Assim,

(...) o corpo é uma construção sobre a qual são conferidas diferentes marcas em diferentes tempos, espaços, conjunturas econômicas, grupos sociais, étnicos, etc. Não é, portanto, algo dado a priori, nem mesmo é universal: o corpo é provisório, mutável e mutante, suscetível a inúmeras intervenções consoante o desenvolvimento científico e tecnológico de cada cultura bem como suas leis, seus códigos morais, as representações que cria sobre os corpos, os discursos que sobre ele produz e reproduz. (Goellner, 2003, p. 28)

Compartilhamos da assertiva da autora, pois compreendemos que o corpo é uma construção cultural e sede de signos sociais - nele estão inscritos as regras, as normas e os valores de uma sociedade específica, por ser ele o meio de contato primário de um indivíduo com o ambiente que o cerca.

Por este motivo, pensar o corpo como algo produzido na/pela cultura é simultaneamente um desafio e uma necessidade. Se outrora a cultura das instituições de acolhimento era controlar os corpos, hoje a aspiração deveria ser oposta, no sentido de liberá-los no âmbito moral e até mesmo religioso. Nesse sentido, o brincar pode ser um espaço para a interiorização de novas regras e mesmo um projeto de resistência.

\section{Brincar e(é) transgredir}

O brincar das crianças que estão em situação de acolhimento é constituinte do cotidiano e necessita ser investigado com atenção. Esta dimensão pôde ser observada na rotina da instituição em determinado momento do dia (turno vespertino). As brincadeiras não estão desvinculadas de algumas normas de convívio no interior da casa, que forjam corpos infantis institucionalizados, 
passando por constantes processos formativos que oscilam entre a disciplina e a transgressão.

Sobre esse assunto, as contribuições dos estudos de Foucault $(2001,1987)$ são pertinentes quando lançamos um olhar para a infância vivida em situações de acolhimento, especialmente ao que tange à docilização e transgressão dos corpos, pois a criança, enquanto ser instituído social e historicamente, é influenciado por relações de poder e dominação.

No decorrer das atividades emergiram situações de estranhamento e desconforto das acadêmicas do Curso de Pedagogia que conduziam o projeto de extensão, pois nestas ocasiões estão sendo reproduzidas algumas normas de controle que já foram assimiladas pelas crianças durante as brincadeiras de imitação:

Catarina ${ }^{4}$ colocou várias bonecas em um Bebê Conforto ${ }^{5}$ para dormir e começou a falar baixinho para não os acordar. Neste momento a observava de longe, estava com o Josué na coberta, brincando. (...) eu bati palmas forte para o Josué e Catarina veio em minha direção e disse: "quem tá batendo palma? ". Respondi: sou eu! E bati mais duas vezes. Catarina deu um grito: "Eu já falei que não é pra bater palma! ". (Diário de Bordo, 28 de março de 2018)

A educação do corpo ocorre a todo momento, desde a forma de sentar até a maneira de comer, entre outras interações sociais. Esses aspectos remetem a traços históricos de uma educação corporal que é, segundo Leite e Silva (2005, p. 63), “(...) baseada no excesso de rotina e na tentativa de padronização de comportamentos que, por vezes, acarreta uma desvalorização sistemática das subjetividades envolvidas".

4 Cadeira anatômica confortável própria para acomodar bebês, geralmente utilizada em carro ou casa.

5 Pseudônimo.
A infância institucionalizada é um dos meios legalizados para governar as crianças e moldar as suas condutas, com o intuito de otimizar o tempo e civilizar os corpos. Dito doutra forma, as sanções adotadas pelo Acolhimento visam práticas que resultam no seu disciplinamento. Verifica-se, portanto, que dialogar sobre o brincar nos leva a tratar de um corpo que historicamente foi negligenciado na formação humana, seja no âmbito pessoal (restrição das emoções), seja nas instituições, com o domínio e limitação de movimentos (Camargo, 2014). Os aspectos evidentes, em maior ou menor grau, provocam discussões sobre as práticas corporais na infância, pois são restritos os ambientes para as crianças brincarem, fatores que limitam a exploração do movimento.

Pertinente às observações das práticas inerentes ao funcionamento do Serviço de Acolhimento, nos aspectos da institucionalização, nas expressões verbais e não verbais das crianças enquanto brincam, podemos evidenciar alguns aspectos que precisam ser analisados. Para provocar movimentos de reflexão-ação é preciso colocar sob tensão discursos-práticas recorrentes, muitas vezes enraizados.

As etapas disciplinatórias requerem a utilização de determinadas técnicas, como a distribuição das crianças nos espaços, o cumprimento de rotinas e horários. Todas as quartas-feiras, após horário de lanche (15 horas), as crianças participam do projeto e a prioridade é proporcionar experiências corporais e lúdicas. Este é o horário destinado ao brincar. Compreendemos ser este um momento oportuno para a criação e exploração dos sentidos, para experiências corporais de emancipação da criança. Nessa conjuntura, a transgressão torna-se necessária, se realmente há intenções de o adulto propor situações capazes de promover rupturas dos modelos impostos.

Conhecer como se expressa a educação do corpo no cotidiano da infância no contexto de Acolhimento é um constante desafio. A linguagem corporal é uma forma de 
expressão que assume diversas faces e poderá assumir a função de interlocução ou produção entre sujeitos, que exige do mediador disponibilidade para provocar experiências. Entretanto, os condicionamentos impostos pela ordem geralmente não admitem transgressão de regras e normas, muito comuns no ato de criar. Contraditoriamente, parece-nos que o exercício criativo é, fundamentalmente, um ato transgressivo. Arriscamos afirmar que, quanto maior a incorporação do regramento institucional, menor a criatividade. As atitudes desviantes das crianças variavam em quantidade e natureza, mas é certo que, em algum momento, elas descumprirão o que os adultos julgam ser o adequado. Esta dimensão de desconforto evade do controle dos adultos - vai além, ou mesmo contra os espaços institucionalizadores que, não raro, coíbem o brincar.

Contribui para essa reflexão o estudo de Nazario (2015, p. 07), ao destacar como a ordem discursiva produz efeitos sobre a organização institucional em que habitam adultos e crianças, que tecem suas relações sobre determinadas circunstâncias. A lógica institucional revela o lugar das crianças "Na casa", porém elas vivem outra temporalidade, não linear, que indicam outros sentidos - "(...) as crianças como sujeitos que se apropriam, reinventam e reproduzem o mundo, sugerem a possibilidade de um estar Em Casa".

As observações realizadas permitiram constatar o uso prolongado dos espaços internos por parte das crianças, geralmente no segundo andar da/na casa, onde passam parte do dia assistindo televisão ou se entretendo com alguns brinquedos. Nestes ambientes a presença de adultos geralmente é pautada pelo controle sobre as ações das crianças, com intervenções em possíveis conflitos e desconfortos, bem como para assegurar a ordem. Quando as crianças são levadas para brincar em áreas abertas, especialmente no campo e parquinho, localizados do lado externo do prédio, percebemos que as crianças ao enxergarem os brinquedos, empolgam-se, saem correndo naquela direção, como em um momento de liberdade.

Contudo, é comum as cuidadoras alertarem: “- não vão no sol, pois está muito quente! " (Diário de Bordo, 04 de abril de 2018). Cabe destacar a importância das cuidadoras se integrarem às brincadeiras conjuntamente com as crianças, o que promoveria o envolvimento na atividade lúdica.

As saídas ao ar livre para a promoção de brincadeiras também podem assumir a forma de resistência e desvio do instituído, conforme contatamos em uma das atividades realizadas com as crianças, que consistiu em montar cabanas no ambiente externo, ao lado do parque, com acesso aos balanços, escorregador e gira-gira. Foram levados lençóis, tatames, mesas, cadeiras, brinquedos diversos (carros, bonecas, trator, bolas, animais) e livros com imagens ilustrativas. Após as cabanas estarem estruturadas, chegaram as crianças, que ficaram encantadas com o lugar, que tomaram a iniciativa de mudar desses objetos.

Na área externa da casa são proporcionados movimentos com maior liberdade corporal, pois a amplitude do terreno é propícia para a experimentação de variadas práticas. Nessas situações a linguagem corporal das crianças e as manifestações de pequenas transgressões no brincar e na desobediência às regras, em momentos de disputa pelos brinquedos e/ou pela atenção de quem as acompanhava emergiam. A constante des obediência é contrária a uma das funções do Biopoder - organizar e regulamentar as condutas para manter a ordem e disciplina. A disciplina aumenta as forças do corpo (em termos econômicos de utilidade) e diminui essas mesmas forças (em termos políticos de obediência).

Provenientes de situação de desamparo, não seria sem conflitos e resistências que as crianças aceitariam imposições de qualquer natureza sobre seus atos. Segundo Leite e Silva (2005, p. 78) as relações sociais em diferentes espaços, as atividades livres e lúdicas, a flexibilização de horários "(...) constituem-se como possibilidades de ressignificar, transformar ou mesmo deixar de lado a repetição excessiva, por vezes mecânica, da rotina diária e de sua tendência à alienação. " 
As rotinas estruturadas associadas a determinadas práticas, que não estimulam a autonomia, nem respeitam a individualidade das crianças, constituem dispositivos que, por meio do controle, mortifica o eu e dociliza o corpo. Portanto, tanto a transgressão quanto o disciplinamento do corpo infantil institucionalizado, que varia de intensidade entre os residentes, leva em consideração pelo menos dois fatores: o nível de dependência e o tempo de permanência - quanto mais dependente, mais encurvada ao desejo da instituição torna-se. Importante destacar também que os bebês são aqueles que estão em uma situação de maior dependência e fragilidade. Porém, são os corpos menos docilizados, pois estão em processos de introjeção e criação de subjetividades. Não é de se estranhar, portanto, que geralmente sejam os corpos mais rebeldes.

É evidente que a presença semanal das acadêmicas na instituição modificou a rotina por algumas horas. Em determinada ocasião, ao se deslocarem com as crianças para uma área aberta, com mesas e cadeiras, puderam desenvolver uma atividade com massas de modelar comestivel de diversas cores e sabores. As criações emergiram em vários formatos, e, muitos delas representavam animais, brinquedos e adornos. As crianças maiores auxiliavam as pequenas, ajudavam-nas na produção de pulseiras. Para Leite e Silva (2005) nesse jogo de relações entre sujeitos, o corpo está sendo educado e constituído, no tempo-espaço da vida.

Brincadeiras podem gerar desordem, barulho e sujeira, portanto, não raro, são motivos de questionamento ou mesmo desconfiança pelos adutos. Em contraponto, as experiências proporcionadas têm valorizado a corporalidade das crianças em sua singularidade, experienciadas por outra temporalidade, diferente dos adultos, que tendem a criar modos de subjetivação atravessados por dispositivos para a manutenção da ordem estabelecida que, por vezes, oscila entre a resistência das crianças e as normatizações, ou mesmo contradiz no que tange a preocupação com a formação e ocupação no tempo e controle dos corpos.

Outra atividade proposta pelo projeto foi o Cesto do Tesouro, uma coletânea de objetos de uso cotidiano, utilizada com o fim de ampliar as experiências sensoriais, que oportuniza às crianças escolher e explorar os brinquedos disponibilizados, sendo que os objetos eram alterados paulatinamente, e os cestos substituídos por caixas de papelão, que foram pintadas por elas mesmas. Nos encontros seguintes, concomitante à pintura das caixas, afixamos um grande papel na parede, de modo a formar um painel, para servir como tela e oportunizar novas experiências plásticas:

As crianças foram indagadas e provocadas a criar e interagir com a tela. No início foi colocada pouca tinta à disposição. Algumas imediatamente utilizaram os recursos, outras logo colocaram as mãos nas tintas, misturando-as e criando novas cores. Paulatinamente, as crianças empolgaram-se e a atividade tornou-se mais interessante, envolvendo a todas. Transcorridos alguns minutos, elas estavam com roupas e corpos pintados.

Intentamos com essa dinâmica romper com modelos rígidos na infância, constituindo, dessa maneira, lugares e tempos capazes de flexibilizar a rotina na instituição, que é permeada por "dispositivos civilizadores" (Vaz et al., 2009). A flexibilização do tempo e lugar torna os encontros menos rígidos, mais fluídos, menos controlados pelos ponteiros do relógio. A rotina institucional tradicionalmente é composta por ações que buscam legitimidade disciplinar, capazes de gerar alguma estabilidade e/ ou provocar adaptação que, com distintas nuances, está presente à serviço da regulação das relações.

Para Vaz (2002) a constante busca pela ordem, asseio, segurança e proteção, parece compor um conjunto de processos sócio-sanitários, não isentos de certa busca pela neutralização da sujeira (e da infância e seus desajustes), 


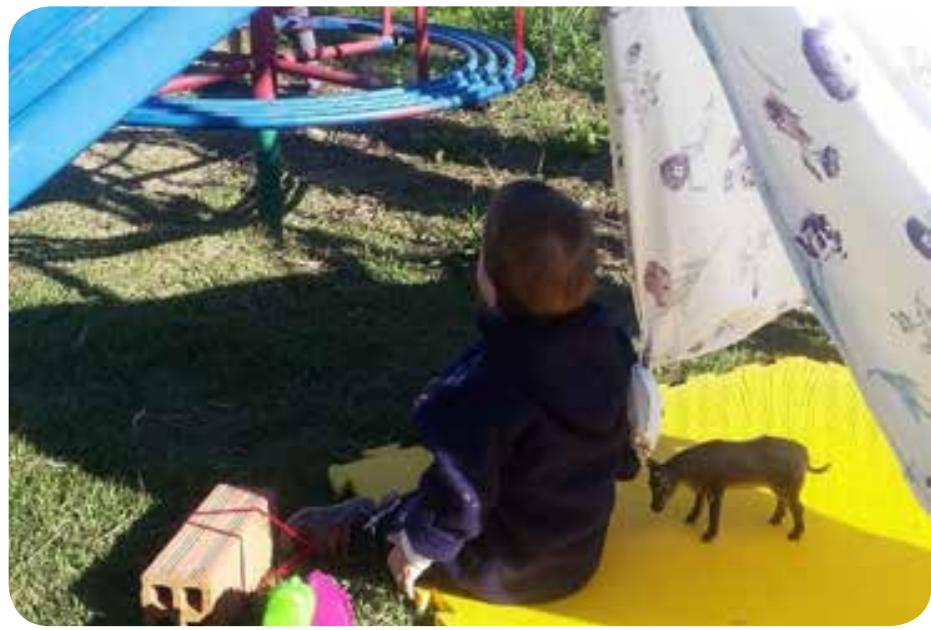

Imagem 1. Construção de cabana e interação com brinquedos ao ar livre. (Ciudad de Chapecó, 2018). Fonte: Acervo do autor.

de forma a tornar as crianças independentes, capazes de regular seu próprio corpo por meio do autocontrole.

Nesta relação ambígua entre disciplina e autonomia, os cuidados de si encontram seu destino na educação do corpo. Nesse movimento é importante questionar o que tem sido definido como "certo" e "errado" corporalmente.

Vivemos um paradoxo cotidiano quando nos expressamos em relação ao corpo e suas expressões nos ambientes educacionais. O corpo é, por excelência, o órgão das paixões, dos desejos, do cansaço, das dores, dos sofrimentos, da "preguiça", das fortes e fracas emoções, da fome, da sede, das vontades fisiológicas, das muitas pulsões, enfim, em uma palavra, do descontrole. Nesse sentido, faz parte do imaginário educacional a idéia de que deve o corpo ser educado, disciplinado, que não devem ser poupados esforços no sentido de colocá-lo "na linha", na retidão dos bonscostumes, do autocontrole (Vaz, 2002, p. 3).

A educação corporal no cotidiano é constituída por diversos mecanismos de controle do corpo, sendo que as brincadeiras podem revelar ações contra aquilo que parece excessivo, descontrolado, mais próximo à natureza. Nesse sentido, o brincar não está distante de outras formas de controle e ajustamento. Fazer o contraponto, de modo a favorecer arranjos que contemplam situações de "transgressão" entre crianças de diferentes idades, permite colocar o tema sob tensão, de modo a repensar o modus operandi da instituição.

\section{Considerações Finais}

Durante as inserções semanais do projeto, as experiências proporcionadas privilegiaram as experiências e a movimentação corporal pelo brincar, sem o intento de controlar e civilizar os corpos ou mesmo com a função de ocupação do tempo. A importância que o brincar tem para a vida das crianças nem sempre é compreendida pelas instâncias formadoras e socializadoras, em que a ordem resiste em ser alterada.

No cerne das instituições reside um conjunto de normas e rituais corporais, impregnados pelas singularidades da 


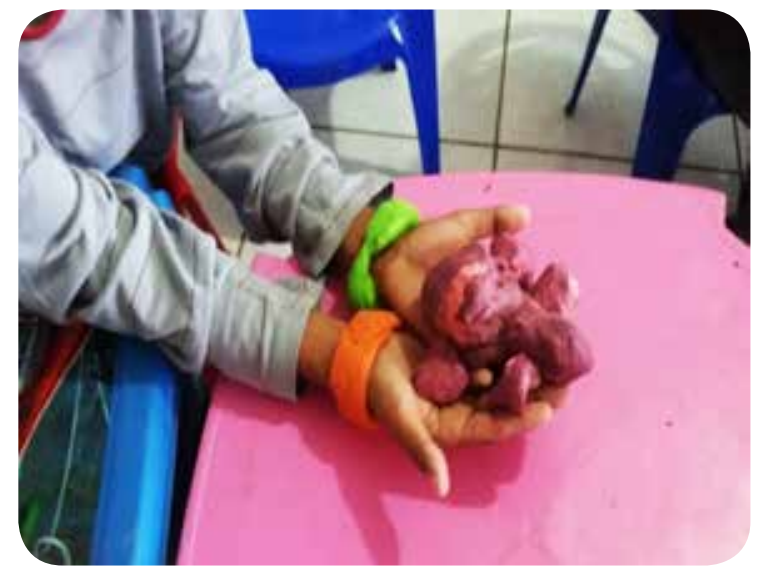

Imagem 2. Criança cria caranguejos e pulseiras com massas coloridas de modelar. (Ciudad de Chapecó, 2018) Fonte: Acervo do autor.

realidade desses sujeitos e da própria instituição. Além das necessidades e cuidados do/com o corpo, higiene pessoal, alimentação e descanso, outras práticas perpassam os diversos momentos do dia, forjando a educação corporal.

As evidências demonstraram que esses espaços requerem outras leituras, práticas e interpretações dos corpos infantis, por vezes invisibilizados e/ou compreendidos como transgressores. $\mathrm{O}$ brincar tem as suas repercussões, que oscilam entre a tentativa de controle das crianças pelos adultos e o iminente descontrole.

Outrossim, os momentos de intervenção que foram propostos subvertem o ordenamento linear da rotina institucional e podem ser compreendidos como um movimento de ruptura, importante no processo formativo da corporalidade das crianças.

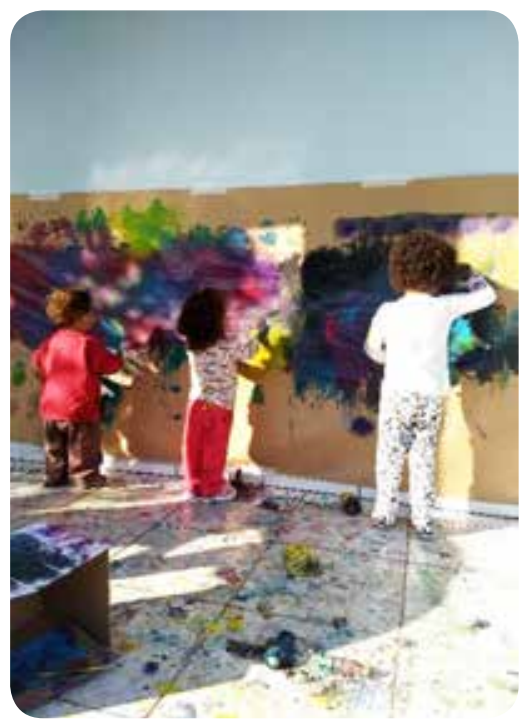

Imagem 3. Crianças utilizam as próprias mãos para pintar a tela. (Ciudad de Chapecó, 2018). Fonte: Acervo do autor.

Em síntese, o brincar é uma manifestação da cultura lúdica infantil, capaz de estimular as interações com a realidade e ampliar as experiências, signos e linguagens diversas das crianças, inclusive a linguagem corporal.

\section{Referências}

Arpini, D. M. (2001). "Sonhar a gente sonha": representações de sofrimento e exclusão em adolescentes em situação de risco. Tese de Doutorado, Pontifícia Universidade Católica, São Paulo, SP, Brasil.

Camargo, D. (2014). O brincar corporal na educação infantil: reflexões sobre o educador, sua ação e formação. Curitiba: Intersaberes.

\section{Crespo, J. (1990). A História do Corpo. RJ: Bertrand Brasil.}

Estatuto da criança e do adolescente: Lei n. 8.069, de 13 de julho de 1990, Lei n. 8.242, de 12 de outubro de 1991 (2001). (3a ed.). Brasília: Câmara dos Deputados, Coordenação de Publicações. 
Ferreira, M. (2002). “- A gente aqui o que gosta mais é de brincar com os outros meninos! " - as crianças como atores sociais e a (re) organização social do grupo de pares no cotidiano de um Jardim de Infância. Dissertação de doutoramento em Ciências da Educação, Universidade do Porto, Faculdade de Psicologia e Ciências da Educação, Porto, Portugal.

Foucault, M. (2009). Ditos e Escritos III: Estética: literatura e pintura, música e cinema (2a ed.). Rio de Janeiro: Forense Universitária.

Foucault, M. (2001). Vigiar e Punir: história da violência nas prisões. São Paulo: Vozes.

Foucault, M. (1987). Microfísica do poder. Rio de Janeiro: Graal.

Goellner, S. (2003). A Produção cultural do Corpo. In Louro,

G., e Neckel, J. Corpo, Gênero e Sexualidade, (pp. 28-40). Petrópolis, RJ: Vozes.

Goffman, E. (2005). Manicômios, prisões e conventos. São Paulo: Perspectiva.

Leite, J. O., e Silva, A. M. (2012). Educação de corpo, infância e juventude no cotidiano de um abrigo. In Arroyo, M. G., e

Silva, M. R. (Org.). Corpo infância: exercícios tensos de ser criança; por outras pedagogias dos corpos. Petrópolis, RJ: Vozes.
Maffesoli, M. (2005). A Sombra de Dionísio: contribuição a uma sociologia da orgia. (2a ed.). São Paulo: Zouk.

Motta, M. B. (Org.). (2012). Michel Foucault: segurança, penalidade e prisão. (Coleção Ditos e Escritos, Vol. VIII, 2a ed.). Rio de Janeiro: Forense Universitária.

Nazario, R. (2015, outubro). Entre estar na Casa e estar em Casa: modos de ser criança em um contexto de Acolhimento Institucional. Anais da 37 Reunião Anual ANPEd, Florianópolis, SC, Brasil, 15.

Peres, W. S. (2011). Travestis: corpos nômades, sexualidades múltiplas e direitos políticos. In: Souza, L. A. F., Sabatine, T.

T. e Magalhães, B. R. (Org.). Michel Foucault: sexualidade, corpo e direito, (pp. 69-104). São Paulo: Cultura Acadêmica.

Soares, C. L. (2003). Apresentação. Pro-Posições, 14(2), pp.15-19.

Vaz, A. F. (2002, janeiro). Aspectos, contradições e mal-entendidos da educação do corpo e a infância. Motrivivência, (19), pp. 1-7.

Vaz, A. F., RC. Vieira, C. L N., Gonçalves, G. C., e Gonsalves, M. C. (2009). Corpo, infância, cuidados de si: Educação Física no contexto da Educação Infantil. Inter-ação 34(01), pp. 199-214. 